\title{
Recent Introduction and Recombination in Colletotrichum acutatum Populations Associated with Citrus Postbloom Fruit Drop Epidemics in São Paulo, Brazil
}

\author{
Maisa Ciampi-Guillardi, Cristina Baldauf, Anete Pereira Souza, Geraldo José Silva-Junior, and Lilian Amorim
}

First and fifth authors: Department of Plant Pathology and Nematology, University of São Paulo, CEP 13418-900, Piracicaba, SP, Brazil; first and third authors: Genetic Engineering and Molecular Biology Center, University of Campinas, CEP 13083-875, Campinas, SP, Brazil; second author: Department of Animal Sciences, Federal Rural University of Semiarid Region, CEP 59625-900, Mossoró, RN, Brazil; and fourth author: Fundecitrus, Fund for Citrus Protection, CEP 14807-040, Araraquara, SP, Brazil.

Accepted for publication 2 January 2014.

\begin{abstract}
Ciampi-Guillardi, M., Baldauf, C., Souza, A. P., Silva-Junior, G. J., and Amorim, L. 2013. Recent introduction and recombination in Colletotrichum acutatum populations associated with citrus postbloom fruit drop epidemics in São Paulo, Brazil. Phytopathology 104:769-778.

Citrus crops in São Paulo State, Brazil, have been severely affected by postbloom fruit drop disease (PFD), which is caused by Colletotrichum acutatum. This disease leads to the drop of up to $100 \%$ of young fruits. Previous studies have assumed that this pathogen exhibits a clonal reproductive mode, although no population genetic studies have been conducted so far. Thus, the genetic structure of six C. acutatum populations from sweet orange orchards showing PFD symptoms was deter-

recent introduction from a common source, since this pathogen was introduced in Brazil only very recently. Sharing haplotypes among orchards separated by $400 \mathrm{~km}$ suggests the natural dispersal of fungal propagules, with the possible involvement of pollinators. A significant population expansion was detected, which was consistent with an increase in host density associated with crop expansion toward new areas across the state. Findings of moderate to high levels of haplotypic diversity and gametic equilibrium suggest that recombination might play an important role in these pathogen populations, possibly via parasexual reproduction or a cryptic sexual cycle. This study provides additional tools for epidemiological studies of $C$. acutatum to improve prevention and management strategies for this disease.
\end{abstract} mined using nine microsatellite markers, enabling inference on predominant mode of reproduction. C. acutatum populations exhibit a nearly panmictic genetic structure and a high degree of admixture, indicating either ongoing contemporary gene flow at a regional scale or a
Additional keywords: fungal dispersal, microsatellites, reproductive strategies, sweet orange.
Filamentous fungi of the genus Colletotrichum (teleomorph Glomerella) are economically significant plant pathogens worldwide, acting as causal agents of anthracnose and other diseases of the leaves, stems, and fruits of numerous plant species, including several important crops (70). C. acutatum causes postbloom fruit drop disease (PFD) in citrus crops by infecting the flower petals, resulting in peach to orange lesions on open flowers and flower buds under favorable conditions (58), leading to a subsequent abscission of the fruitlet with the calyx, and leaving only the floral disk attached to the twig $(2,58)$. The disease was first described in Belize in 1979 (27), and during the 1980s it was reported in several locations from Central America, Mexico, and the United States (USA), as well as Argentina and Brazil (8). Later, PFD was distributed to all of the citrus-growing areas of the Americas, most likely by movement of plant material bearing appressoria (58). In Brazil, the disease has been reported since the 1970s, first in the orchards of the Rio Grande do Sul and later in São Paulo State (59). The disease is most severe when consecutive rainy days occur during bloom (2). Severe outbreaks have

Corresponding author: M. Ciampi-Guillardi;

E-mail address: maisaciampi@gmail.com

* The $\boldsymbol{e}$-Xtra logo stands for "electronic extra" and indicates that the online version contains one supplementary table.

http://dx.doi.org/10.1094/PHYTO-06-13-0165-R

(C) 2014 The American Phytopathological Society occurred in Florida (USA) and Brazil, leading to a drop of up to $100 \%$ of the young fruits $(63,74)$. All sweet orange varieties cultivated in São Paulo State are susceptible to this disease, which has been controlled by protectant fungicide sprays (31).

C. acutatum usually produces abundant conidia in acervuli on diseased petals under moist conditions, and the conidia are typically dispersed by rain-splash to healthy flowers over short distances, although the dispersal of droplets by wind during rainstorms can reach much greater distances $(2,47,58)$. With consecutive cycles of infection in sweet orange flowers, citrus PFD can reach large areas in a single season $(2,58)$. Because flowers are the only susceptible tissue and they occur only seasonally, the fungus survives as appressoria on the surface of leaves, twigs, and persistent calyces, or as a quiescent infection of vegetative structures after the plants are established $(58,79)$. Quiescent infections occur prior to the development of PFD symptoms. After blooming, leachates from flowers induce the production and germination of conidia that infect and, subsequently, colonize new flowers to produce acervuli $(58,79)$.

C. acutatum associated with PFD is thought to spread via asexual propagules (conidia) from infected tissues, since there is no evidence that ascospores act in the dispersal of any disease caused by $C$. acutatum $(57,58)$. Because no teleomorph has been reported for $C$. acutatum so far (19), it is considered to have only a minor role in the pathogen life cycle (58). Sexual reproduction for $C$. acutatum was previously described based on the mating of compatible strains in the laboratory $(33,34)$, but the teleomorph 
Glomerella acutata was recently revaluated and assumed to be an interspecific hybrid between C. acutatum and C. fioriniae (19), which is known to reproduce sexually (49). The parental strains used in the crosses could have originated from geographically distant populations that could have lost their post-mating reproductive isolation barriers as noted in other fungal groups (19). The production of a sexual state in nature has been reported for C. acutatum on Vaccinium corymbosum (highbush blueberry) in Norway (71). However, without performing sequence-based identification, and considering that the blueberry pathogen is usually $C$. fiorinae, the identity of this population and thus the presence of $C$. acutatum-producing teleomorphs in nature remains uncertain (19). Additional studies on the biology and population genetics of $C$. acutatum would be instructive in terms of its population dynamics, means of survival and dissemination, and the importance of recombination to its life cycle $(19,58)$.

At a global scale, $C$. acutatum populations display variable levels of genetic and phenotypic diversity. Low genotypic diversity was detected in C. acutatum isolates from strawberry and citrus in Florida (76), just as a few clonal genetic groups were observed among $C$. acutatum isolates from olives in Portugal (72). Very little genetic diversity was found in $C$. acutatum isolates in association with citrus PFD from Brazil, Costa Rica, Belize, Mexico, the Dominican Republic, and Florida, which did not form phylogenetic groups based on their geographic origin (57). There was also no haplotype variation among $C$. acutatum isolates for either ITS-5.8S rDNA or partial glyceraldehyde-3-phosphate dehydrogenase $(G 3 P D)$ sequences and there was a single nucleotide difference in the glutamine synthase $(G S)$ sequences associated with PFD in Florida (46). On the other hand, seven vegetative compatibility groups (VCGs) were identified in Brazil among $13 \mathrm{C}$. acutatum isolates from distinct hosts, which were not related to their geographic origin (29), and nine VCGs were detected in a single apple orchard infected with $C$. acutatum in the United States (34). Discrepancies in sequence tree topologies from $C$. acutatum isolates from distinct hosts suggest a history of recombination among them in Florida, where novel C. acutatum genotypes might be produced from lineages with no apparent sexual stage (46).

Reproductive strategies, geographic patterns, ongoing gene flow, and the historical movement of fungal strains can be inferred by using population structure information of plant-pathogenic fungi $(5,14,41,69)$, which reflects the evolutionary potential of pathogens, an important input for appropriate long-term disease management strategies (52). Therefore, a pathogen population with high genetic variation has higher evolutionary potential and is more likely to quickly adapt to unfavorable conditions such as resistant hosts or fungicide application than a population with low genetic diversity, which has a more limited potential to persist in the field over many seasons (52). Gene flow among populations and recombination are two important sources of new allelic and genotypic variation that may act to increase genotypic or haplotypic diversity in a population. These are essential biological forces to consider in disease management because they can have profound effects on the management of outbreaks (52).

Fungal species have great diversity in their modes of reproduction, ranging from fully asexual lineages to obligate outcrossers, with direct consequences for genetic variation and persistence within populations; therefore, making inferences about predominant reproductive modes is essential to understanding fungal life cycles and evolution $(38,53)$. Asexual lineages may be inclined to accumulate deleterious alleles and might be unable to rapidly adapt to heterogeneous environments (44). On the other hand, sexual or parasexual recombination generates genotypic diversity in pathogen populations, allowing rapid adaptation to unfavorable conditions (61). Many fungi have the ability to switch between clonal and recombinant reproduction during their life cycles (73), which provides great adaptive potential once they can produce new genotypes through recombination, and rapidly spread the highly adapted traits through clonal reproduction $(5,52)$.

Despite its negative impact on sweet orange production, little information is available about the epidemiology of PFD disease, which remains unknown in terms of its inoculum variability inside orchards, distance of inoculum dispersal, and level of clonality of $C$. acutatum. Studying genetic variation within and among $C$. acutatum populations could provide information on their geographical patterns and explain the potential for the fungus to change in response to environmental pressures. In aiming to address these questions, the objectives of this study were designed to assess the degree of haplotypic diversity and population differentiation in $C$. acutatum populations associated with PFD in six sweet orange orchards. We used nine microsatellite markers that were recently developed for the species (13) to study the geographic distribution of genetic diversity at the population level. Based on the typical conidia dispersal over short distances and the lack of evidence for the role of ascospores in the life cycle of $C$. acutatum, we tested the following two hypotheses: (i) that the pathogen was composed of subdivided or well differentiated populations across sweet orange orchards; and (ii) that these $C$. acutatum populations were clonal in structure. A high degree of population differentiation, low haplotypic diversity (few distinct haplotypes detected at high frequencies), and significant gametic disequilibrium would be expected under these hypotheses, as supported by earlier studies of this pathogen. The low levels of host genetic diversity imposed low selective pressure on the pathogen, so we expected the clonal spread of a few virulent and well-adapted fungal strains to be most common.

\section{MATERIALS AND METHODS}

Sampling and isolation of $\boldsymbol{C}$. acutatum. Flowers showing typical symptoms of blossom blight were collected from six commercial sweet orange orchards that were naturally infected across São Paulo State, Brazil. The flowers were collected while the orchards were in bloom during 2008 and 2009. A description of the sampling sites is given in Table 1 and their relative position is illustrated in Figure 1. It was possible to track the origin of citrus seedlings in three out of six sampled orchards; all of the seedlings came from nurseries located in São Paulo State. Citrus seedlings planted in Taquarituba came from nurseries located in different municipalities, such as Casa Branca, Gavião Peixoto, Novo Horizonte, and Mendonça. Citrus seedlings planted in Santa Cruz do Rio Pardo were locally produced or came from nurseries located in Engenheiro Coelho, Limeira, Sales Oliveira, and Mendonça. In Gavião Peixoto, citrus seedlings were obtained from nearby nurseries. The origin of citrus seedlings is unknown for the other three sampled orchards. Most of the orchards from which samples were taken had received two to four fungicide sprays (carbendazim or difenoconazole), depending on the weather conditions. The only sweet orange orchard where no chemical control was used against any citrus disease was Pedranópolis (PD). Pairwise approximate distances between sampled orchards ranged from 98 to $467 \mathrm{~km}$ (Table 2). In each sweet orange orchard, only one infected flower with PFD symptoms was collected from each orange tree distributed randomly throughout a single orchard. The number of sampled trees ranged from 19 to 69 , depending on the orchard size and disease incidence (Table 1). For fungal isolations, symptomatic petals were surface disinfested by placing them in $95 \%$ ethanol for $30 \mathrm{~s}$, then $1 \%$ sodium hypochlorite for $1 \mathrm{~min}$, and rinsed twice in sterile distilled water. Small pieces of diseased tissue were plated on agar medium (15 g of agar per liter) and incubated at $25^{\circ} \mathrm{C}$ for 3 days. The fungi hyphal tips emerging from the tissue pieces were transferred to potato dextrose agar (PDA) media and grown at $25^{\circ} \mathrm{C}$. All isolates were single-spored prior to use. Monosporic cultures were stored on dry filter papers colonized by the fungus at $-20^{\circ} \mathrm{C}(40)$. 
DNA extraction and genotyping. For the DNA extractions, isolates were grown for 7 days on PDA dishes at $25^{\circ} \mathrm{C}$. Mycelium plugs were collected from the media and ground in sterilized sand, and fungal genomic DNA was extracted following the method by Kuramae-Izioka (40). The identification of each fungal isolate as $C$. acutatum was performed by selective amplification of part of the ITS-5.8S rDNA region with the specific primer CaInt2 (5'-GGCCTCCCGCCTCCGGGCGG-3') (62) in combination with primer ITS4 (5'-TCCTCCGCTTATTGATATGC-3') (78).

Multilocus haplotypes (MLHs) of C. acutatum isolates were characterized with nine microsatellite loci (CA04, CA08, CA11, CA12, CA13, CA15, CA16, CA26, and CA27), which were individually amplified by polymerase chain reaction (PCR) as previously described (13). Amplifications were performed in a $15 \mu \mathrm{l}$ volume containing $5 \mathrm{ng}$ of template DNA, $0.8 \mathrm{mM}$ of fluorescently labeled forward and common reverse primers, $20 \mathrm{mM}$ Tris- $\mathrm{HCl}, 50 \mathrm{mM} \mathrm{KCl}, 1.5 \mathrm{mM} \mathrm{MgCl}, 0.15 \mathrm{mM}$ of each $\mathrm{dNTP}$, and $1 \mathrm{U}$ of Taq DNA polymerase in a PTC-100 thermal cycler (MJ Research, Waltham, MA) using the following program: $96^{\circ} \mathrm{C}$ for $1 \mathrm{~min}$, followed by 30 cycles of denaturation at $94^{\circ} \mathrm{C}$ for $1 \mathrm{~min}$, specific annealing temperature $\left(57\right.$ to $\left.62^{\circ} \mathrm{C}\right)$ for $1 \mathrm{~min}$ and a final extension of $72^{\circ} \mathrm{C}$ for $10 \mathrm{~min}$. The amplified microsatellite fragments were electrophoretically separated on an automated DNA sequencer ABI 377 (Applied Biosystems, Foster City, CA) using GS-500 TAMRA (Applied Biosystems) as an internal size standard. Raw data were collected, scored, and exported as a fragment size for simple sequence repeats (SSRs) using GeneScan v3.1.2 and Genotyper v2.5.2 software (Applied Biosystems). To avoid any error bias, the genotype of each individual was confirmed by two independent repeats, revealing that the amplification patterns were highly reproducible. Statistical binning of the alleles into fragment size categories consistent with the repeat unit increments was performed with FLEXIBIN software (B. Amos, Cambridge University, UK).

Data analysis. An MLH code was constructed for each $C$. acutatum isolate according to the observed allele sizes across the nine microsatellite loci. Only one allele was amplified per locus, as expected for a haploid organism. Isolates with the same alleles at all loci were treated as clones of the same MLH. Every group of $C$. acutatum isolates collected from the same orchard was considered as part of a distinct population, using the definition of a population as a group of organisms of the same species occupying a particular space at a particular time (39). Genetic and haplotypic diversity analyses were performed by using a complete data set from $C$. acutatum isolates. A clone-corrected data set was gen-

TABLE 1. Estimates of genetic and genotypic diversity among Colletotrichum acutatum isolates from six sweet orange orchards in São Paulo State, Brazil ${ }^{\mathrm{a}}$

\begin{tabular}{|c|c|c|c|c|c|c|c|c|c|c|c|}
\hline Population & Code & $N^{\mathrm{b}}$ & $\mathrm{MLHs}^{\mathrm{c}}$ & $\begin{array}{l}\text { Clonal } \\
\text { fraction }\end{array}$ & $\hat{G}^{\mathrm{d}}$ & $\hat{G} / N^{\mathrm{e}}$ & $N_{\mathrm{A}}^{\mathrm{f}}$ & $A_{\mathrm{R}}^{\mathrm{g}}$ & $H^{\mathrm{h}}$ & $r_{\mathrm{D}}{ }^{\mathrm{i}}$ & $P$ \\
\hline Barretos & BT & 19 & 9 & 0.53 & $4.81 \mathrm{a}$ & 25 & $2.11 \pm 0.26$ & $2.11 \mathrm{a}$ & $0.32 \mathrm{a}$ & 0.086 & 0.06 \\
\hline Gavião Peixoto & GP & 20 & 12 & 0.40 & $5.13 \mathrm{a}$ & 26 & $2.56 \pm 0.41$ & $2.52 \mathrm{ab}$ & $0.38 \mathrm{a}$ & -0.057 & 0.92 \\
\hline Mogi-Guaçu & MO & 24 & 14 & 0.42 & $5.76 \mathrm{a}$ & 24 & $2.67 \pm 0.37$ & $2.46 \mathrm{ab}$ & $0.30 \mathrm{a}$ & -0.021 & 0.73 \\
\hline Pedranópolis & PD & 27 & 19 & 0.30 & $14.88 \mathrm{~b}$ & 55 & $4.78 \pm 0.55$ & $4.00 \mathrm{c}$ & $0.56 \mathrm{~b}$ & 0.019 & 0.20 \\
\hline Santa Cruz do Rio Pardo & ST & 64 & 32 & 0.50 & $14.95 \mathrm{~b}$ & 23 & $4.33 \pm 0.58$ & $3.13 \mathrm{ac}$ & $0.41 \mathrm{ab}$ & 0.007 & 0.37 \\
\hline Taquarituba & TQ & 69 & 44 & 0.36 & $23.45 \mathrm{c}$ & 34 & $5.67 \pm 0.55$ & $3.69 \mathrm{bc}$ & $0.47 \mathrm{ab}$ & 0.024 & 0.06 \\
\hline Total & & 223 & 101 & 0.55 & 17.77 & 8 & $3.69 \pm 0.26$ & 10.33 & 0.35 & - & - \\
\hline
\end{tabular}

${ }^{a}$ Means followed by the same letter are not significantly different $(P \geq 0.05)$ in pairwise comparisons based on 1,000 permutations.

b Sample size.

c Number of distinct multilocus haplotypes.

d Stoddart's genotypic diversity (68).

e Stoddart's genotypic diversity scaled by sample size.

f Number of distinct alleles averaged across loci \pm standard deviation.

g Allelic richness with rarefaction to 19 (24).

h Nei's unbiased genetic diversity averaged over all loci and corrected for sample size (54).

i Index of association measures (51) and associated $P$ values as determined by 1,000 randomizations.

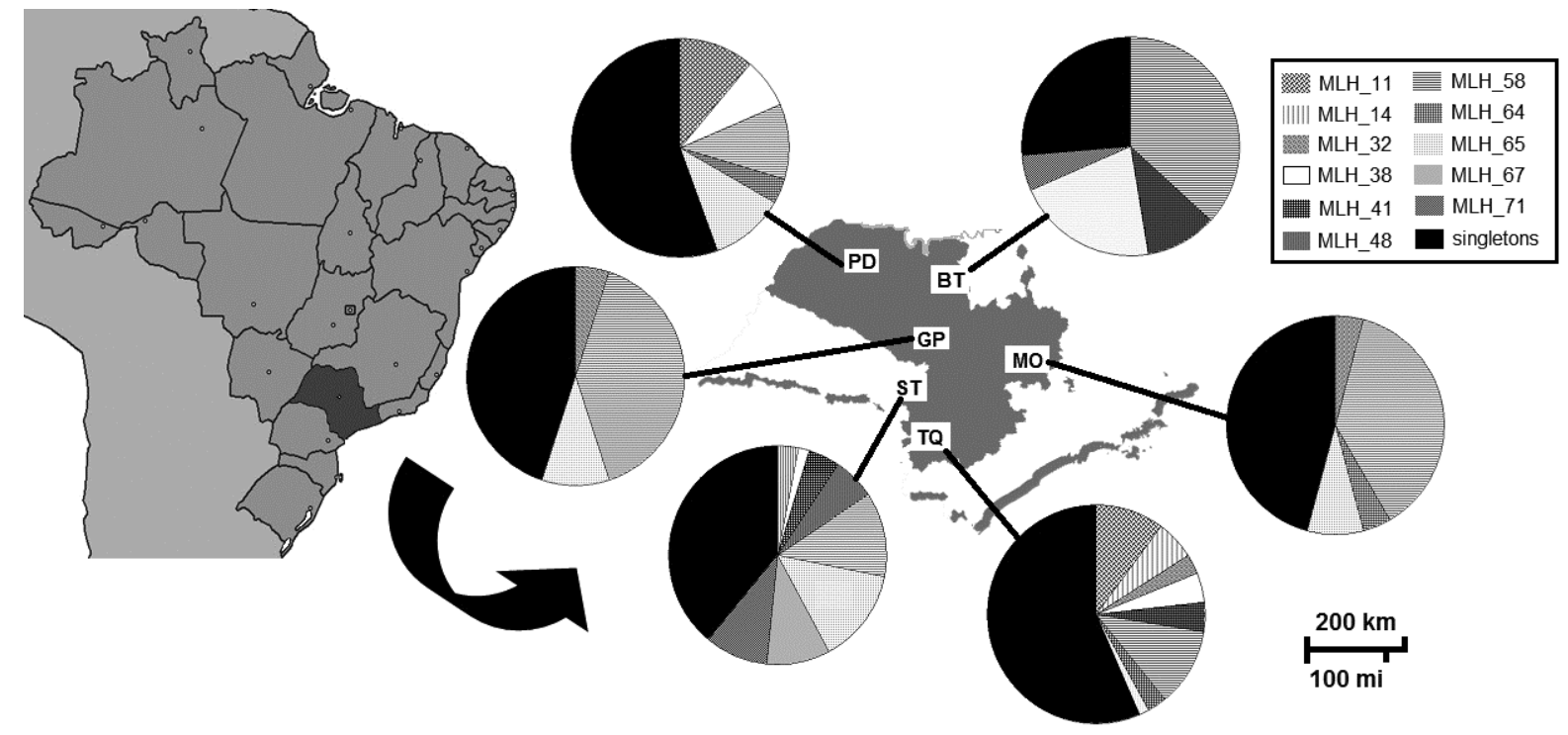

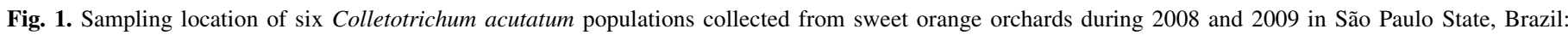

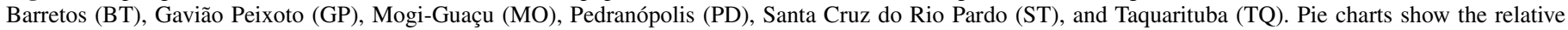

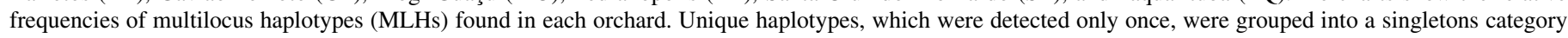
and represented as black in the pie charts. The highlighted area on the map represents the extent of the citrus growing area in the state. 
erated for all other population-level genetic analyses, in which each MLH was represented only once in each population. This approach was taken to minimize the effects of clonal reproduction during epidemics on population differentiation estimates.

Genetic and haplotypic diversity. Allele frequencies and the number of alleles $\left(N_{\mathrm{A}}\right)$ per locus (and across loci in each population) were estimated using GenAlex v.6.4 software (R. Peakall and P. Smouse, The Australia National University, Canberra, Australia), which was also used for the identification of private alleles. To compare allele frequencies among populations with different sample sizes, we estimated allelic richness $\left(A_{\mathrm{R}}\right)$ and unbiased Nei's gene diversity $(H)(54)$ by using a rarefaction method (24), which enables comparisons among populations of unequal sample sizes by calculating the expected number of alleles in a subsample of $n$ genes corresponding to the sample size of the smallest population, which is based on 1,000 permutations, using FSTAT v.2.9.3 software (J. Goudet, University of Lausanne, Switzerland).

To determine the haplotypic diversity of $C$. acutatum populations, unique MLHs were identified in GenAlex v.6.4, as well as MLHs shared among populations. Stoddart and Taylor's genotypic diversity index $(\hat{G})$ was estimated for each population (68) and scaled by sample size $(\hat{G} / N)$ using GenoDive software (P. Meirmans, Universiteit van Amsterdam, Netherlands). A bootstrap resampling method was implemented in GenoDive and used to test whether these indices were significantly different among C. acutatum populations on the basis of 1,000 permutations with subsampling (48).

Population differentiation. The distribution of genetic diversity within and among $C$. acutatum populations was estimated by using a hierarchical analysis of molecular variance (AMOVA) and the squared number of repeat differences among haplotypes $\left(R_{\mathrm{ST}}\right)$ to calculate distances, assuming the stepwise-mutation model of microsatellite evolution, or SMM (64). This analysis was performed in Arlequin v.3.1.1 software (L. Excoffier, G. Laval, and S. Schneider, University of Bern, Switzerland), with significance testing by using 5,000 permutations. Pairwise comparisons among populations were conducted on the basis of Slatkin's $R_{\mathrm{ST}}$, assuming that a value of $R_{\mathrm{ST}}=0$ indicates panmictic populations; an $R_{\mathrm{ST}}<0.05$ denotes negligibly differentiated populations; $0.05<R_{\mathrm{ST}}$, 0.25 indicates that populations are moderately differentiated and an $R_{\mathrm{ST}}>0.25$ reflects highly differentiated populations.

To test for the existence of divergent genetic pools among C. acutatum populations, we used a model-based Bayesian clustering method to assign MLHs to distinct genetic clusters $(28,60)$ without considering information on their geographic origin, which was performed in STRUCTURE v.2.3 software (J. K. Pritchard, X. Wen, and D. Falush, University of Chicago, IL). For this approach, multilocus genotype data are used to define a set of populations with distinct allele frequencies and to probabilistically assign individuals to populations. We used an admixture ancestry model-based clustering method, allowing mixed ancestry among individuals from different populations $(K)$ with correlated allele frequencies among populations. Ten independent runs were performed using 500,000 Markov chain steps after a burn-in period of 200,000 steps, assuming 1 to 7 subpopulations ( $K=1$ to $7)$. We compared the likelihood estimate of each of the $K$ values to determine the number of $K$ populations present in the $C$. acutatum pool of haplotypes. The number of genetically discrete populations was estimated on the basis of the maximum log probability of data $\operatorname{Ln} P(D)$ for different values of $K$ and by using the statistic $\Delta K(25)$, which considers the rate of change in $\operatorname{Ln} P(D)$ values among successive $K$ runs to account for patterns of dispersal that are not homogeneous among populations.

Since the STRUCTURE algorithm maximizes both the HardyWeinberg equilibrium and linkage equilibrium among unlinked loci within clusters, the existence of an important asexual component in the life cycle of some species could lead to spurious assignments (36). Thus, we also applied a principal coordinate analysis (PCoA) to corroborate the patterns of clustering proposed by STRUCTURE, which is a nonparametric method that does not rely on any assumption of random mating or linkage equilibrium and is suitable for analyzing partially clonal species. PCoA was performed with GenAlex v.6.4, based on a matrix of Euclidean distances between all pairs of MLHs (65).

Reproductive mode. To test for clonality, the nonrandom association of alleles between pairs of loci was measured by using the index of association $\left(I_{\mathrm{A}}\right)$, a multilocus linkage disequilibrium estimate based on the variance of pairwise distances between individuals, such as the number of loci at which they differ (51), in MultiLocus v.1.3 software (P. M. Agapow and A. Burt, University College London, UK). Because the magnitude of $I_{\mathrm{A}}$ depends on the number of loci studied, we also estimated $r_{\mathrm{D}}$, a locus number independent measure (1). An $I_{\mathrm{A}}$ value close to zero indicates random mating and significant gametic disequilibrium is expected in asexual or inbreeding populations. To examine whether the observations deviated significantly from the null hypothesis of no linkage disequilibrium among loci, the observed variance was compared with the expected variance under random mating, which was obtained after reshuffling the alleles within each clone-corrected population data set over 1,000 permutations.

TABLE 2. Probabilities of multilocus haplotypes (MLHs) of Colletotrichum acutatum $\left(P_{\text {gen }}\right)$ and their reoccurrence resulting from distinct sexual events $\left(P_{\text {sex }}\right)$ within sweet orange orchards in São Paulo State, Brazil

\begin{tabular}{|c|c|c|c|c|c|c|c|c|c|c|c|c|c|c|c|c|c|c|c|}
\hline \multicolumn{20}{|c|}{ Frequency by population } \\
\hline MLH & & & & & Alleles & & & & & $\mathrm{BT}$ & GP & $\mathrm{MO}$ & PD & ST & TQ & Total & $P_{\text {gen }}$ & $P_{\text {sex }}$ & $P^{\mathrm{a}}$ \\
\hline MLH11 & 127 & 138 & 179 & 123 & 108 & 135 & 115 & 227 & 232 & 0 & 0 & 0 & 3 & 0 & 7 & 10 & 0.001 & $2.3 \times 10^{-7}$ & 0.000 \\
\hline MLH14 & 127 & 138 & 179 & 123 & 108 & 137 & 115 & 227 & 232 & 0 & 0 & 0 & 0 & 2 & 4 & 6 & 0.006 & $2.9 \times 10^{-3}$ & 0.040 \\
\hline MLH31 & 129 & 138 & 179 & 121 & 108 & 137 & 115 & 227 & 232 & 0 & 0 & 1 & 0 & 0 & 1 & 2 & 0.002 & 0.087 & 0.293 \\
\hline MLH32 & 129 & 138 & 179 & 121 & 110 & 137 & 115 & 227 & 232 & 0 & 1 & 1 & 0 & 0 & 2 & 4 & 0.004 & 0.014 & 0.112 \\
\hline MLH34 & 129 & 138 & 179 & 121 & 110 & 139 & 115 & 227 & 232 & 0 & 1 & 0 & 0 & 0 & 1 & 2 & 0.001 & 0.022 & 0.144 \\
\hline MLH38 & 129 & 138 & 179 & 123 & 108 & 135 & 115 & 227 & 232 & 0 & 0 & 0 & 2 & 1 & 3 & 6 & 0.010 & 0.030 & 0.162 \\
\hline MLH39 & 129 & 138 & 179 & 123 & 108 & 135 & 117 & 227 & 232 & 0 & 0 & 0 & 1 & 0 & 1 & 2 & 0.006 & 0.359 & 0.562 \\
\hline MLH41 & 129 & 138 & 179 & 123 & 108 & 137 & 115 & 227 & 232 & 2 & 0 & 0 & 0 & 3 & 3 & 8 & 0.044 & 0.770 & 0.889 \\
\hline MLH45 & 129 & 138 & 179 & 123 & 108 & 137 & 117 & 229 & 232 & 0 & 0 & 0 & 2 & 1 & 0 & 3 & 0.008 & 0.286 & 0.531 \\
\hline MLH58 & 129 & 138 & 179 & 123 & 110 & 137 & 115 & 227 & 232 & 7 & 8 & 9 & 3 & 8 & 8 & 43 & 0.083 & 0.020 & $4.34 \times 10^{-5}$ \\
\hline MLH60 & 129 & 138 & 179 & 123 & 110 & 137 & 115 & 227 & 264 & 0 & 0 & 0 & 0 & 2 & 1 & 3 & 0.003 & 0.023 & 0.148 \\
\hline MLH61 & 129 & 138 & 179 & 123 & 110 & 137 & 115 & 229 & 232 & 1 & 0 & 1 & 1 & 0 & 0 & 3 & 0.029 & 0.958 & 0.985 \\
\hline MLH63 & 129 & 138 & 179 & 123 & 110 & 137 & 117 & 227 & 232 & 1 & 0 & 0 & 0 & 1 & 0 & 2 & 0.045 & 1.000 & 1.000 \\
\hline MLH64 & 129 & 138 & 179 & 123 & 110 & 137 & 117 & 229 & 230 & 0 & 0 & 1 & 1 & 0 & 2 & 4 & 0.001 & $1.9 \times 10^{-5}$ & 0.002 \\
\hline MLH65 & 129 & 138 & 179 & 123 & 110 & 137 & 117 & 229 & 232 & 4 & 2 & 2 & 3 & 9 & 1 & 21 & 0.016 & $1.0 \times 10^{-5}$ & 0.000 \\
\hline MLH71 & 129 & 138 & 179 & 123 & 110 & 139 & 117 & 229 & 232 & 1 & 0 & 0 & 0 & 6 & 0 & 7 & 0.004 & $2.9 \times 10^{-5}$ & 0.002 \\
\hline
\end{tabular}

${ }^{\text {a }}$ Likelihood of $P_{\text {gen }}$ and $P_{\text {sex }}$ estimates. 
In order to test whether all MLH replicates are the result of a clonal spread rather than a distinct recombination event, probability $P_{\text {sex }}$ was estimated by MLGsim v.2.0 software (A. B. F. Ivens, M. V. Sanden, and J. Bakker, University of Groningen, Netherlands), based on the number of loci and allelic frequencies $(3,56)$. The $P$ value for testing the significance of $P_{\text {sex }}$ for each repeated MLH was estimated by simulating 1,000 randomly mating populations of size $N$ with observed allele frequencies to generate a null distribution of $P_{\mathrm{sex}}$ against which the actual value of $P_{\text {sex }}$ could be compared (67).

Demographic fluctuations. A test for detecting evidence of historical changes in population size was performed with the Bottleneck v.1.2 software (J. M. Cornuet, G. Luikart, and S. Piry, INRA, Montpellier, France). Gene diversity was estimated for each population and for each locus as expected under the assumption of an equilibrium between mutation and drift (which is called expected gene diversity or heterozygosity), and the result was compared with the gene diversity directly calculated from data set allele frequencies (or observed gene diversity). In a population that has undergone a bottleneck, or a recent reduction in its effective size, gene diversity is higher than expected at equilibrium because of a high frequency of rare alleles, and the opposite is expected for a population experiencing demographic expansion (15). Gene diversity was estimated under the following two mutation models: the strict stepwise mutation model (SMM), and the two-phase model (TPM), in which $70 \%$ of alleles were attributed to SMM and $30 \%$ to the infinite alleles model (IAM) (20), based on 1,000 replications. One-sided Wilcoxon signed rank tests (43) were performed to evaluate if the allele frequency distribution deviated significantly from the expected distribution under mutation-drift equilibrium.

\section{RESULTS}

Genetic and haplotypic or clonal diversity. A total of 223 C. acutatum fungal strains were isolated across the six sampled orchards, which were assumed to fall into six geographic pathogen populations and are reported as such from this point on. The average number of alleles per locus across the nine microsatellite loci was $3.69 \pm 0.26$ (standard deviation) within the entire collection of $C$. acutatum isolates. The number of alleles at each locus across populations ranged from 6 (loci CA08 and CA12) to 15 (locus CA27). All loci exhibited one most common allele except for loci CA13 and CA16, which had two most common alleles across populations. The number of effective alleles was similar among loci and ranged from $1.17 \pm 0.14$ for locus CA08 to $1.95 \pm 0.26$ for locus CA15 (Supplemental Table). CA08 was the locus with the lowest value for unbiased Nei's gene diversity $(0.10 \pm 0.08)$, while CA15 $(0.48 \pm 0.09)$ and CA16 $(0.48 \pm 0.02)$ were the loci with the highest values. For each population, the number of alleles ranged from $2.11 \pm 0.26$ (population BT) to $5.67 \pm 0.55$ (population TQ), which was proportional to their respective sample sizes (Table 1). When estimates of allelic richness across loci were considered, pop PD showed the highest significant number of alleles based on the size of the smallest population (BT, $N=19$ ) (Table 1$)$. The average gene diversity per locus $(H)$ across populations ranged from $0.096 \pm 0.08$ (CA08) to $0.476 \pm 0.02$ (CA16). Mean gene diversity across all loci was moderate $(0.314 \pm 0.03)$, with similar values across all populations, ranging from 0.22 to 0.49 (Table 1 ).

Among the 223 C. acutatum isolates, 101 distinct MLHs were identified across the six populations, indicating the presence of clones at distinct scales (Table 1). The most frequent MLH was detected 43 times in all populations, accounting for $19 \%$ of the total sample and was most likely the founder strain that initiated the epidemic. This haplotype was found in the two most distant orchards, namely Mogi-Guaçu (MO) and Pedranópolis (PD), which were approximately $467 \mathrm{~km}$ apart. This clone was dominant in all but the PD population, in which two other MLHs were detected at equal frequencies. The 15 other MLHs (11.5\% of total) were shared among at least two populations, but the majority of 85 MLHs (65\%) occurred just once. Based on the estimates and significance of $P_{\text {sex }}$, we could not reject the null hypothesis that 10 out of 16 shared MLHs arose independently by recombination, once the $P_{\text {sex }}$ estimates were high and did not significantly differ from zero $(0.11 \leq P \leq 0.99)$, suggesting that these shared MLHs likely resulted from independent sexual reproductive events (Table 2). When those MLHs were included again in the data set, after having been removed during clone-correction, the results were essentially the same. For the most frequent MLHs (MLH 58 and MLH 65), found in every population, the $P_{\text {sex }}$ values were significant $\left(P=4.34 \times 10^{-5}\right.$, and $P=0.0$, respectively) and likely to have resulted from clonal propagation among the analyzed C. acutatum populations.

Total haplotypic diversity was moderate $(0.45)$ and the clonal fraction, or the proportion of isolates sharing the same MLHs, ranged from 0.30 in population PD, where 19 MLHs were detected in 27 isolates, to 0.53 in population BT, in which nine MLHs were distinguished out of 19 isolates (Table 1). As with the number of observed alleles, estimates of Stoddart's genotypic diversity were proportional to $C$. acutatum population sample sizes, with lower values for the smallest (4.81 in BT) and higher values for the largest population (23.45 in TQ). When those estimates were scaled to the maximum number of genotypes expected based on the smallest sample size, the highest genotypic diversity was found in population PD, which also had the highest estimates of allelic richness and Nei's genetic diversity (Table 1).

Population differentiation. Hierarchical AMOVA revealed that $98.3 \%$ of genetic diversity was distributed within populations, and only $1.7 \%$ among the sampled orchards. A corresponding low total population differentiation (global $\Phi_{S T}=0.017$ ) was found among $C$. acutatum populations and was not statistically significant $(P=0.11)$. All but one pairwise comparison among $C$. acutatum populations revealed nonsignificant population differentiation (Table 3$)$, except between ST and TQ $\left(R_{\mathrm{st}}=\right.$ $0.036 ; P=0.03$ ), which were negligibly differentiated.

This low genetic differentiation was in accordance with global clustering results (Fig. 2). The level of affiliation for individual genotypes is presented in Figure 2. The most likely number of clusters $(K)$, which was the one with the highest likelihood $[\operatorname{Pr}(K)]$ based on Evanno's $\Delta K$ method, was obtained for $K=3$. Regardless of the value of $K$, the populations displayed various and admixed membership to the proposed genetic clusters. Therefore, there was evidence of admixture in all six sampling points, with fungal individuals from distinct populations sharing the same genetic clusters, indicating a genetic continuity for $C$. acutatum within São Paulo State. When the genetic diversity distribution among groups proposed by Bayesian clustering analysis was evaluated, hierarchical analyses of molecular variance revealed

TABLE 3. Pairwise population differentiation among Colletotrichum acutatum populations associated with postbloom fruit drop in sweet orange orchards of São Paulo State, Brazil ${ }^{\mathrm{a}}$

\begin{tabular}{lcccccc}
\hline & \multicolumn{6}{c}{ Population } \\
\cline { 2 - 7 } Population & BT & GP & MO & PD & ST & TQ \\
\hline BT & $\ldots$ & 154 & 189 & 307 & 324 & 385 \\
GP & -0.063 & $\ldots$ & 286 & 197 & 187 & 233 \\
MO & -0.051 & -0.052 & $\ldots$ & 467 & 339 & 416 \\
PD & 0.062 & 0.049 & 0.047 & $\ldots$ & 345 & 325 \\
ST & 0.006 & 0.009 & 0.010 & 0.021 & $\ldots$ & 98 \\
TQ & 0.031 & 0.017 & 0.016 & 0.019 & $0.036^{\text {b }}$ & $\ldots$
\end{tabular}

${ }^{\text {a }} R_{\mathrm{ST}}$ values are presented below the diagonal and approximate geographic distances are shown above the diagonal (in kilometers).

b Significant genetic differentiation $(P \leq 0.05)$ in pairwise comparisons based on 1,000 permutations. 
that most of the variation (77.5\%) was distributed within STRUCTURE clusters. The three genetic clusters of $C$. acutatum isolates inferred from genetic clustering methods accounted for a greater proportion of the genetic variance $(22.5 \%)$ than population-based (2\%) hierarchical structures.

Genetic similarity among isolates was additionally visualized using PCoA, which revealed a clear overlap among isolates from all six C. acutatum populations (Fig. 3). The first two coordinates together explained $59.7 \%$ of the genetic variation. Overall, the haplotypes identified in the six fungal populations formed a continuous cloud of points across axes 1 and 2 and no distinct MLH clusters were evident.

Reproductive mode. Based on multilocus linkage disequilibrium (LD) estimates, the null hypothesis for a random association of alleles between pairs of loci was not rejected for all fungal populations (Table 1) with low and non-significant $I_{\mathrm{A}}$ (ranging from -0.007 to -0.051 ) and $r_{\mathrm{D}}$ values, suggesting free genetic recombination in these pathogen populations investigated. These estimated LD results were consistent with gametic equilibrium associated with a recombinant mode of reproduction for $C$. $a c u$ tatum populations in sweet orange orchards sampled in São Paulo.

Estimates of $P_{\text {sex }}$ values, which measure the chance that identical MLHs have been generated from asexual reproduction (67), estimated for the $16 \mathrm{MLHs}$ shared between at least two $C$. $a c u$ tatum populations, revealed that six of them most likely arose from selfing, including the two most common MLHs, which were observed in all evaluated fungal populations (Table 2). The $P_{\text {sex }}$ values indicated that the remaining 10 shared haplotypes could have arisen from distinct recombination events that happened independently in each population, on the basis of the allele frequencies at each locus for each MLH (Table 2).

Demographic fluctuations. The consequences of demographic fluctuations on genetic diversity were assessed by a heterozygosity excess test. The outcome of the demographic fluctuation analyses indicated that most $C$. acutatum populations might not
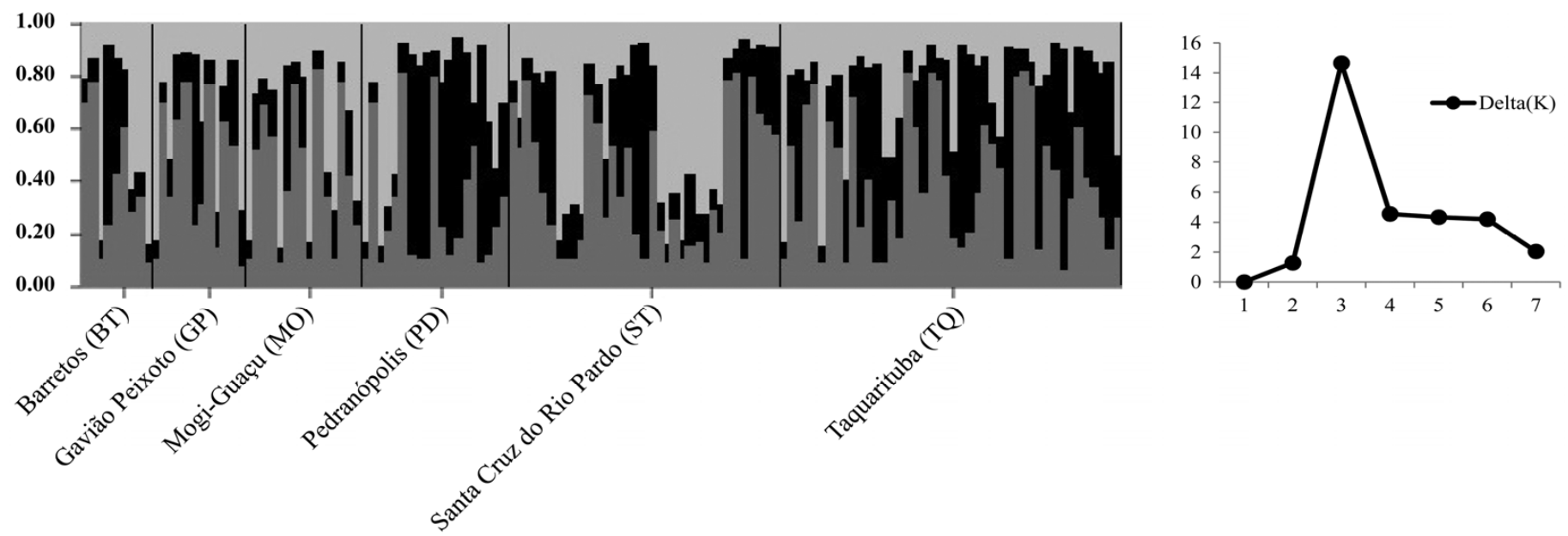

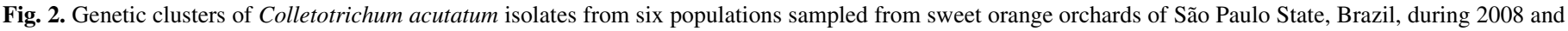

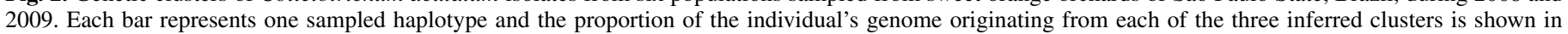
shades of gray. The most likely number of clusters $(K)$, based on Evanno's $\Delta K$ method, is also presented.

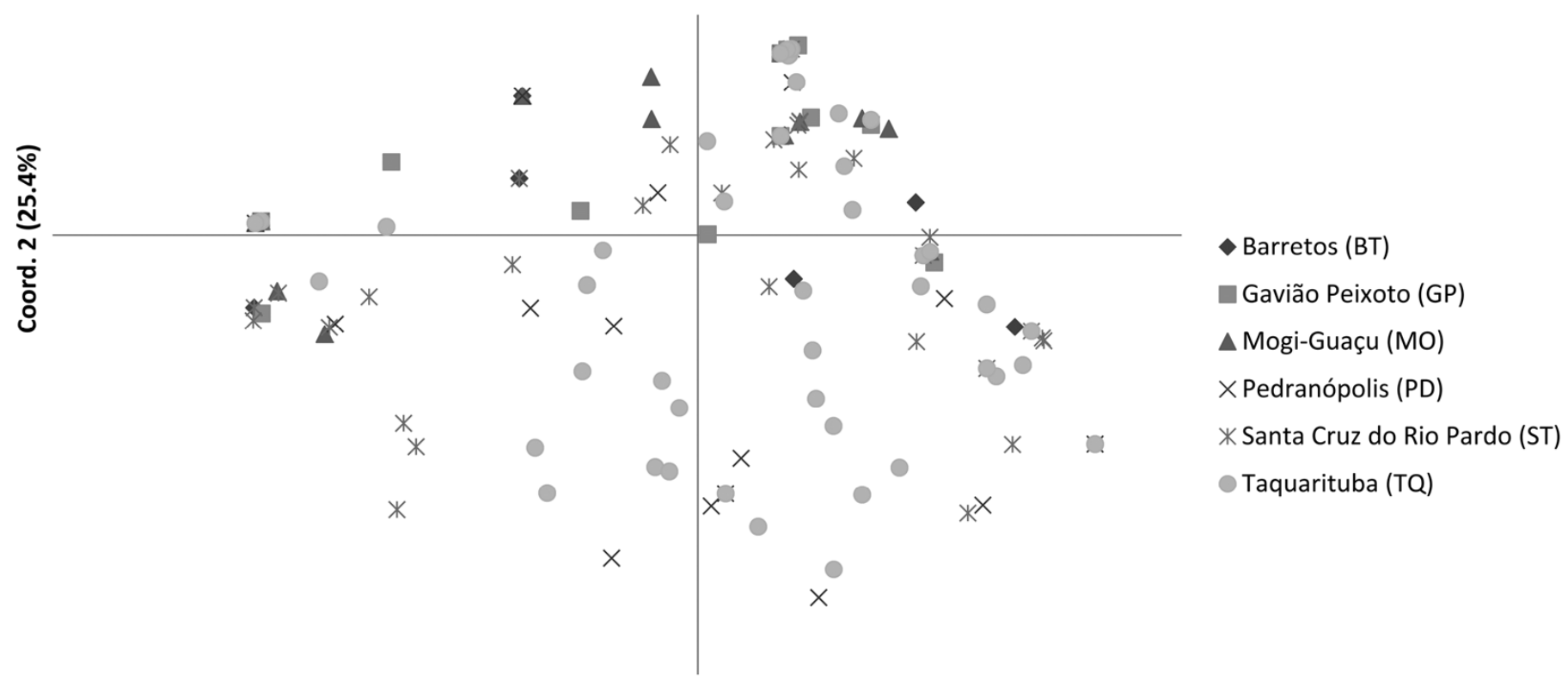

Coord. 1 (34.3\%)

Fig. 3. Two-dimensional principal coordinate plot based on pairwise genetic distances between simple-sequence repeat haplotypes from 223 isolates of Colletotrichum acutatum from six populations collected from sweet orange orchards during 2008 and 2009 in São Paulo State, Brazil. Percent variation explained by each axis (principal coordinate) is shown in parentheses. 
be considered to be at demographic stability because they had more loci exhibiting a significant deficit in gene diversity than expected at equilibrium (Table 4). Wilcoxon rank tests revealed that populations $\mathrm{MO}, \mathrm{PD}, \mathrm{ST}$, and TQ deviated significantly from mutation-drift equilibrium $(P<0.05)$ (Table 4$)$ under both models of evolution (TPM and SMM), which is consistent with a recent population demographic expansion. On the other hand, it seems that populations BT and GP have not been submitted to recent demographic changes (population expansion or reduction) or the changes were too small to be detected under the given statistical power of the tests performed here.

\section{DISCUSSION}

This investigation represents the first study of $C$. acutatum population genetic structure as associated with PFD in sweet orange orchards of São Paulo State, Brazil. Moderate to high levels of haplotypic diversity were detected in C. acutatum isolates, which were notably distinct from those found in earlier studies of this pathogen, where isolates associated with citrus PFD in the Americas were highly similar to one another considering the distinct DNA sequences in a whole collection of isolates from PFD-affected citrus $(46,57)$. The current study has focused on a population-level distribution of genetic diversity across pathogen populations sampled from distinct orchards in São Paulo State, thereby allowing us to evaluate the genetic patterns at a regional spatial scale. We based our analysis on microsatellite markers, which are expected to be more sensitive to recent phylogeographic and demographic events (e.g., bottlenecks or population expansions) due to their higher rate of evolution in comparison to other molecular markers (41). The high variation typical of microsatellite loci make them particularly sensitive for detecting population changes (66) and were shown here to be very effective in the intraspecific characterization of $C$. acutatum populations. The low levels of genetic and genotypic diversity previously reported for $C$. acutatum could be due to the nonspecific and insufficient polymorphic markers used, which makes impractical any predictable conclusions on the reproductive mode or genetic structuring in this species.

Because $C$. acutatum from PFD-affected citrus was assumed to be clonal, with no sexual stage reported for this host in naturally infected orchards (58), we tested the genetic differentiation hypothesis among pathogen populations, with a widespread occurrence of identical and nonrecombinant MLHs, based on the following three criteria: the geographic distances between sampled orchards, the levels of clonality previously reported for the species $(46,57)$, and the genetic uniformity of the host. We also expected to detect fungal populations experiencing significant multilocus linkage disequilibrium once this estimate can be inflated by asexual reproduction (53). Contrary to our initial hypotheses, surprisingly moderate to high haplotypic variation and moderate to low clonal fractions were detected, with no population showing a significant departure from expectations under a random association of alleles. Because our findings did not allow us to confirm our initial hypotheses, we propose the following alternative hypothesis: $C$. acutatum populations were recently introduced from a common and genetically diverse source, having remained undifferentiated because fungal propagules have been naturally and gradually dispersed over at least $400 \mathrm{~km}$ across São Paulo State, following the continuous geographical distribution of the host, with the possible involvement of citrus pollinators and genetic recombination (most likely via hyphal fusion and mitotic recombination at the orchard level).

C. acutatum from PFD-affected citrus was thought to be clonal because no sexual stage has ever been reported in this host (58) nor in any other (19). The frequency distribution of distinct MLHs within population BT indeed suggests that clonal reproduction is dominant in this lineage, with the two most frequent MLHs representing $58 \%$ of all sampled isolates. In contrast, no single MLHs reached frequencies higher than $11 \%$ in PD population, which was the most variable among the examined fungal populations. This striking distinction could be attributed to the fact that the PD population was sampled from the only sweet orange orchard where no chemical control was employed. The selective pressure imposed by fungicide treatment is thought to affect the genetic diversity of fungal pathogens, increasing the frequency of resistant strains. This force could purge the strains that were not so well adapted to the new environment imposed by fungicide application and, consequently, extinguish a considerable part of the pathogen's genetic diversity, leading to the selection of a few asexual haplotypes characterized by broad tolerance for changing environmental or biotic conditions, in accordance with the general-purpose-genotype hypothesis (45).

Within orchards or fields, we also observed a high recombination rate among genotypes: there were few dominant genotypes and gametic equilibrium. Findings of moderate to high levels of haplotypic diversity, nonsignificant $I_{\mathrm{A}}$ values and values close to zero, and nonsignificant $P_{\text {sex }}$ values for most shared MLHs suggested that genetic recombination might play a significant role in the life cycle of these $C$. acutatum populations in sweet orange orchards from São Paulo. These results were surprising, as the presence of two mating types allowing sexual reproduction between fungal strains were never detected in any Colletotrichum species to date (19). If all the pathogen populations were under strict asexual reproduction, a diversification of haplotypes would be expected over time into distinct clonal lineages composed of a set of closely related haplotypes; however, in recombining populations, the exchange of genetic information among individuals should result in a more homogenous population structure (5). Haplotype frequencies were significantly different in some comparisons between $C$. acutatum populations, indicating that particular fungal MLHs were dominant in certain citrus orchards through asexual reproduction. In contrast, the detection of diverse combinations of alleles, resulting in 65\% unique MLHs (singletons), nonsignificant genetic differentiation between most $C$. acutatum populations in pairwise comparisons, a mixed origin for every single sampled isolate, nonsignificant $P_{\text {sex }}$ values for some MLHs concomitantly found in distinct areas, and gametic equilibrium for all populations indicated the occurrence of genetic exchange and recombination, despite the absence of evidence that the fungus has undergone outcrossing in nature $(19,58)$. It is generally expected that recombining populations of plant pathogens will generate and maintain higher haplotypic diversity than asexual populations for the same allele frequencies (53). Given that the presence of teleomorphs in the field has not been documented for C. acutatum during PFD outbreaks so far (58), a more clonal population structure was expected than the actual observed result. The most definitive way to determine if sexual reproduction is occurring in a fungal pathogen population is to find fertile sexual reproductive structures (18). However, the sexual stage of

TABLE 4. Demographic changes in Colletotrichum acutatum populations associated with postbloom fruit drop in sweet orange orchards of São Paulo State, Brazil, under two mutational models of evolution ${ }^{\mathrm{a}}$

\begin{tabular}{lccccc}
\hline & \multicolumn{3}{c}{ TPM } & & \multicolumn{2}{c}{ SMM } \\
\cline { 2 - 3 } \cline { 5 - 6 } Population & Deficit & Excess & & Deficit & Excess \\
\hline BT & 0.055 & 0.961 & & 0.055 & 0.109 \\
GP & 0.156 & 0.875 & & 0.098 & 0.963 \\
MO & 0.010 & 0.994 & & 0.010 & 0.994 \\
PD & 0.014 & 0.990 & & 0.005 & 0.997 \\
ST & 0.005 & 0.010 & & 0.001 & 1.000 \\
TQ & 0.001 & 1.000 & & 0.001 & 1.000 \\
\hline
\end{tabular}

a Stepwise-mutation model (SMM) and two-phased model (TPM). Probability of deviation from mutation-drift equilibrium was assessed using a two-sided Wilcoxon tests (15). 
certain genetic subgroups of $C$. acutatum has only been characterized under laboratory conditions and designated as Glomerella acutata (34), with fertile sexual structures produced as a result of what is now considered an interspecific hybridization event of strains within the $C$. acutatum complex clade $(19,34)$. Thus, the use of molecular analysis for an indirect assessment of recombination in Colletotrichum, instead of a mating observation in the field, is likely to generate a more accurate evaluation of how recombination has been influenced by the population structure of this plant pathogen (16).

Measuring the association of alleles among loci in a population takes only a few recombinant individuals per generation to create enough recombination to reject the null hypothesis of random mating (4). Considering that small amounts of recombination can have a large impact on the population structure, it is possible that C. acutatum is predominantly mitosporic, with rare recombination events, so the moderate to high haplotypic diversity observed here could be the result of somatic recombination, mutation, or immigration of new genotypes from distinct populations (9). The contribution of nonsexual genetic exchange to generate diversity has been clearly demonstrated for $C$. acutatum (29), so that horizontal gene exchange via hyphal fusion among genetically different strains could contribute to the perpetuation of haplotypic diversity and recombination levels observed here. Even if recombination occurs only rarely, large effective populations, as was observed for plant pathogens such as $C$. acutatum, can maintain genetic diversity generated by previously recombinant ancestors, even if the phenomenon no longer occurs (35). These results are consistent with the population structure of many plant pathogens, as characterized by a mixed mode of reproduction, combining genetic recombination and clonal dispersal of a few haplotypes (51). The mechanisms of recombination and sexual production in Colletotrichum are still not fully understood (10), but as in most ascomycetes, sexual development is controlled for one mating type locus (MAT) with two idiomorphs (MAT1-1 and MAT1-2) (75). Although all Colletotrichum strains sampled to date possess only the MAT1-2 idiomorph $(12,17,22)$, it is assumed that they are still capable of undergoing sexual or parasexual recombination (29), since classical genetic studies have indicated the existence of both homothallic and heterothallic isolates (10).

Each of the six C. acutatum populations analyzed in this study comprised fungal isolates of a mixed origin, since only $35 \%$ of the MLHs had $70 \%$ or more of their ancestry assigned to one of the three clusters proposed in Bayesian analysis, and none of them clustered according to their geographical origin. Thus, most of the isolates represent admixed haplotypes among three divergent genetic pools. The spatial distribution of MLHs suggested a considerable genetic recombination among these genetic pools and also reflected a history of multiple introductions of the pathogen since it was first reported in the 1970s. The strong signs of admixture detected may also reflect the commercial trade of nursery-infected seedlings, which are frequently produced in one region and cultivated in another, and could thus contribute to homogenize the pathogen allele frequencies in each orchard. Several of the sampled sweet orange orchards were composed by seedlings of mixed origin, which could have favored the observed admixture pattern among $C$. acutatum isolates. The exchange of plant material with quiescent or latent infections could result in inoculum transmission among orchards, as suggested for $C$. gloeosporioides associated with anthracnose disease of coffee in Vietnam (55).

Virtually no genetic differentiation was observed in the gene frequencies among $C$. acutatum populations of sweet orange orchards across the state, as reflected in the low $R_{\mathrm{st}}$ values ( $2 \%$ of total genetic variation), even among populations sampled in sites more than $400 \mathrm{~km}$ apart. The only exception was between ST and TQ populations, which were negligibly differentiated $\left(R_{\mathrm{st}}=0.036\right.$; $P=0.03)$, and intriguingly, were sampled in the nearest orchards.
As described in the methodology section, the distinct origin of citrus seedlings composing each of these orchards, and the possibility of having been already infected by the pathogen in field nurseries between the 1970s and 2000s, might account for the detected differentiation. The origin of citrus seedlings also offers an explanation for the low degree of differentiation between C. acutatum populations sampled in distant orchards. For instance, even though ST and BT populations were sampled in orchards more than $300 \mathrm{~km}$ apart, they are closely related possibly because part of the citrus seedlings in the ST orchard came from nurseries near BT and MO orchards, and might not be disease-free, because the production and commercialization of citrus seedlings in protected screen-houses has become mandatory in Sao Paulo State only since 2003. Even though asexual spores of $C$. acutatum were assumed to mainly disperse short distances of only a few hundred meters, sweet orange plantations are relatively continuous across São Paulo State, occupying an extended area of approximately 500,000 hectares in the 2012 to 2013 harvest (11). It seems reasonable that the continuity of host population in São Paulo may offer no virtual barrier to a gradual dispersal of the pathogen, leading to a continuous range expansion at a regional geographic scale, reaching most of the citrus growing region, as has already been suggested for other Colletotrichum diseases $(12,17)$. In the field, the spatial pattern of diseased trees was random during PFD epidemics, indicating that inoculum spread was due to mechanisms other than rain splash (63). Recent studies brought to light the possible involvement of citrus pollinators, such as bees, in transporting not only pollen but also conidia, or even pollen infected by conidia (50); citrus pollinators must also be taken into account when considering the fungal spread at a regional scale. The little population differentiation detected could be explained by hypothesizing a steppingstone model of evolution (37), with fungal propagules gradually dispersed over short distances until connecting distant sweet orange orchards over spatial scales of tens to hundreds of kilometers, although the sampling strategy was not specifically designed to test this sort of association. Altogether, these results suggest that the recent introduction from a common source, the continuity in the geographical distribution of the host as well as the long-distance dispersal of fungal propagules by wind-blown rain and possibly by citrus pollinators have been important in keeping these $C$. acutatum populations undifferentiated in the sweet orange orchards from São Paulo State.

Because PFD was first reported in the country only about three decades ago (59), the low subdivision among C. acutatum populations and the spatial distribution of admixed haplotypes inside São Paulo State likely reflect a recent colonization event, with multiple invasions of the pathogen in citrus orchards from a common source, whose sources of introduced lineages are unknown, especially if there has not been enough time for differentiation to arise, as proposed for Venturia inaequalis associated with apples (30). Therefore, multiple introductions from genetically distinct fungal genetic pools, coupled with local recombination of haplotypes, might have generated this rich haplotypic diversity in $C$. acutatum populations associated to citrus PFD in São Paulo. Several studies investigating the genetic diversity of fungal invasive plant-pathogenic species have revealed that, in general, founder populations show notably reduced diversity when compared with source populations $(6,7,23,32,69)$. However, multiple and successive introductions of an invasive plant pathogen from distinct source populations could indeed extenuate the erosion of genetic diversity and even increase the level of genetic variation (21). Multiple introductions may still favor admixture of genetic pools from originally distinct populations, allowing the emergence and spread of new fungal haplotypes that may be better adapted to a new area, which contributes to their invasive success $(7,23,26)$.

In summary, the results of this study demonstrated that $C$. acutatum populations associated with PFD in São Paulo State 
have been recently established from multiple introductions, and have showed moderate to high levels of haplotypic diversity, lack of genetic structure, some genotype flow, population admixture, linkage equilibrium and the signature of demographic expansion, therefore having a mixed mating system, which includes recombination events followed by clonal expansion during the blooming season. According to the risk model framework proposed by McDonald and Linde (52), these characteristics place C. acutatum among pathogens with a high evolutionary potential to adapt to new or changing environments (52). There was evidence of a large dispersal range of fungal propagules at the regional scale, indicating a substantial risk for the spread of mutant alleles that could permit, for instance, the breakdown of fungicide resistance (42). Because all $C$. acutatum populations analyzed here were sampled during established phases of fungal infection, these results represent only a snapshot of the pathogen population structure during a single epidemic, which might be altered according to growing seasons. During different seasons, strains representative of a particular MLH may either increase or decrease in frequency as epidemics progress (according to environmental conditions). Considering that the occurrence of PFD is highly dependent on climatic conditions, which vary by year in Brazil, collecting fungal isolates in new sweet orange orchards and over consecutive years is necessary to further examine temporal changes in the genetic diversity and demography of $C$. acutatum populations of citrus orchards in São Paulo. Such an investigation would assess whether the genetic patterns described here will be conserved across years.

\section{ACKNOWLEDGMENTS}

This research was supported by a grant (2008/54176-4) to the fifth author and a post-doctoral fellowship (2008/55176-8) to the first author from the São Paulo Research Foundation (FAPESP). We are grateful to S. de Afonseca Lourenço and T. de Andrade Eugênio for technical support. We also thank two anonymous reviewers for their valuable comments and constructive suggestions on an earlier version of this article.

\section{LITERATURE CITED}

1. Agapow, P.-M., and Burt, A. 2001. Indices of multilocus linkage disequilibrium. Mol. Ecol. Notes 1:101-102.

2. Agostini, J. P., Gottwald, T. R., and Timmer, L. W. 1993. Temporal and spatial dynamics of postbloom fruit drop of citrus in Florida. Phytopathology 83:485-490.

3. Arnaud-Haond, S., Duarte, C. M., Alberto, F., and Serrão, E. A. 2007. Standardizing methods to address clonality in population studies. Mol. Ecol. 16:5115-5139.

4. Barnes, I., Crous, P. W., Wingfield, B. D., and Wingfield, M. J. 2004. Multigene phylogenies reveal that red band needle blight of Pinus is caused by two distinct species of Dothistroma, D. septosproum and D. pini. Stud. Mycol. 50:551-565.

5. Barrett, L. G., Thrall, P. H., Burdon, J. J., Nicotra, A. B., and Linde, C. C. 2008. Population structure and diversity in sexual and asexual populations of the pathogenic fungus Melampsora lini. Mol. Ecol. 14:3401-3415.

6. Berbegal, M., Pérez-Sierra, A., Armengol, J., and Grünwald, N. J. 2013. Evidence for multiple introductions and clonality in Spanish populations of Fusarium circinatum. Phytopathology 103:851-861.

7. Brewer, M. T., and Milgroom, M. G. 2010. Phylogeography and population structure of the grape powdery mildew fungus, Erysiphe necator, from diverse Vitis species. BMC Evol. Biol. 10:268.

8. Brown, A. E., Screenivasaprasad, S., and Timmer, L. W. 1996. Molecular characterization of slow-growing orange and key lime anthracnose strains of Colletotrichum from citrus as C. acutatum. Phytopathology 86:523-527.

9. Burdon, J. J., and Silk, J. 1997. Sources and patterns of diversity in plantpathogenic fungi. Phytopathology 87:664-669.

10. Cannon, P. F., Damm, U., Johnston, P. R., and Weir, B. S. 2012. Colletotrichum-current status and future directions. Stud. Mycol. 73:181213.

11. Caser, D. V., Camargo, A. M. M. P., Bueno, C. R. F., Camargo, F. P., Angelo, J. A., Olivetti, M. P. D. A., and Francisco, V. L. F. d. S. 2012 Previsões e Estimativas das Safras Agrícolas do Estado de São Paulo, Ano Agrícola 2011/12, $4^{\circ}$ Levantamento, Abril de 2012. Análises e Indicadores do Agronegócio 7.
12. Chen, F., Goodwin, P. H., Khan, A., and Hsiang, T. 2002. Population structure and mating-type genes of Colletotrichum graminicola from Agrostis palustris. Can. J. Microbiol. 48:427-436.

13. Ciampi, M. B., Baldauf, C., Vigna, B. B. Z., Souza, A. P., Spósito, M. B., and Amorim, L. 2011. Isolation and characterization of microsatellite loci in Colletotrichum acutatum, the causal agent of postbloom fruit drop on citrus. Conserv. Gen. Resour. 3:651-654.

14. Ciampi, M. B., Meyer, M. C., Costa, M. J. N., Zala, M., McDonald, B. A., and Ceresini, P. C. 2008. Genetic structure of populations of Rhizoctonia solani AG-1 IA from soybean in Brazil. Phytopathology 98:932-941.

15. Cornuet, J. M., and Luikart, G. 1996. Description and power analysis of two tests for detecting recent population bottlenecks from allele frequency data. Genetics 144(4):2001-2014.

16. Crouch, J. A., Glasheen, B. M., Giunta, M. A., Clarke, B. B., and Hillman, B. I. 2008. The evolution of transposon repeat-induced point mutation in the genome of Colletotrichum cereale: Reconciling sex, recombination and homoplasy in an "asexual" pathogen. Fungal Gen. Biol. 45:190-206.

17. Crouch, J. A., Tredway, L. P., Clarke, B. B., and Hillman, B. I. 2009. Phylogenetic and population genetic divergence correspond with habitat for the pathogen Colletotrichum cereale and allied taxa across diverse grass communities. Mol. Ecol. 18:123-135.

18. Dale, A. L., Lewis, K. J., and Murray, B. W. 2011. Sexual reproduction and gene flow in the pine pathogen Dothistroma septosporum in British Columbia. Phytopathology 101:68-76.

19. Damm, U., Cannon, P. F., Woudenberg, J. H. C., and Crous, P. W. 2012. The Colletotrichum acutatum species complex. Stud. Mycol. 73:37-113.

20. Di Rienzo, A., Peterson, A. C., Garza, J. C., Valdes, A. M., Slatkin, M., and Freimer, N. B. 1994. Mutational processes of simple-sequence repeat loci in human populations. Proc. Natl. Acad. Sci. USA 91:3166-3170.

21. Dlugosch, K. M., and Parker, I. M. 2007. Founding events in species invasions: genetic variation, adaptive evolution, and the role of multiple introductions. Mol. Ecol. 17:431-449.

22. Du, M., Schardl, C. L., Nuckles, E. M., and Vaillancourt, L. J. 2005. Using mating-type gene sequences for improved phylogenetic resolution of Collectotrichum species complexes. Mycologia 97:641-658.

23. Dutech, C., Fabreguettes, O., Capdevielle, X., and Robin, C. 2010. Multiple introductions of divergent genetic lineages in an invasive fungal pathogen, Cryphonectria parasitica, in France. Heredity 105:220-228.

24. El Mousadik, A., and Petit, R. J. 1996. High level of genetic differentiation for allelic richness among populations of the argan tree [Argania spinosa (L.) Skeels] endemic to Morocco. Theor. Appl. Genet. 92:832-839.

25. Evanno, G., Regnaut, S., and Goudet, J. 2005. Detecting the number of clusters of individuals using the software STRUCTURE: a simulation study. Mol. Ecol. 14:2611-2620.

26. Facon, B., Genton, B. J., Shykoff, J., Jarne, P., Estoup, A., and David, P. 2006. A general eco-evolutionary framework for understanding bioinvasions. Trends Ecol. Evol. 21:130-135.

27. Fagan, H. J. 1979. Postbloom fruit drop, a new disease of citrus associated with a form of Colletotrichum gloeosporioides. Ann. Appl. Biol. 91:13-20.

28. Falush, D., Stephens, M., and Pritchard, J. K. 2003. Inference of population structure using multilocus genotype data: linked loci and correlated allele frequencies. Genetics 164:1567-1587.

29. Franco, C. C. S., Sant' Anna, J. R., Rosada, L. J., Kaneshima, E. N., Stangarlin, J. R., and Castro-Prado, M. A. A. 2011. Vegetative compatibility groups and parasexual segregation in Colletotrichum acutatum isolates infecting different hosts. Phytopathology 101:923-928.

30. Gladieux, P., Zhang, X.-G., Afoufa-Bastien, D., Sanhueza, R.-M. V., Sbaghi, M., and Le Cam, B. 2008. On the origin and spread of the scab disease of apple: out of Central Asia. PLoS ONE 3(1):e1455.

31. Goes, A., Garrido, R. B. O., Reis, R. F., Baldassari, R. B., and Soares, M. A. 2008. Evaluation of fungicide applications to sweet orange at different flowering stages for control of postbloom fruit drop caused by Colletotrichum acutatum. Crop Prot. 27:71-76.

32. Goss, E. M., Larsen, M., Chastagner, G. A., Givens, D. R., and Grünwald, N. J. 2009. Population genetic analysis infers migration pathways of Phytophthora ramorum in US nurseries. PLoS Pathogens 5(9):e1000583.

33. Guerber, J. C., and Correll, J. C. 1997. The first report of the teleomorph of Colletotrichum acutatum in the United States. Plant Dis. 81:1334.

34. Guerber, J. C., and Correll, J. C. 2001. Characterization of Glomerella acutata, the teleomorph of Colletotrichum acutatum. Mycologia 93:216229.

35. Hartl, D. L., and Clark, A. G. 1997. Principles of Population Genetics. 3rd ed. Sinauer Associates, Sunderland, MA.

36. Hubisz, M. J., Falush, D., Stephens, M., and Pritchard, J. K. 2009. Inferring weak population structure with the assistance of sample group information. Mol. Ecol. 9:1322-1332.

37. Kimura, M., and Weiss, G. H. 1964. The stepping stone model of population structure and the decrease of genetic correlation with distance. 
Genetics 49:561-576.

38. Kohn, L. M. 1995. The clonal dynamic in wild and agricultural plantpathogen populations. Can. J. Bot. 73:1231.

39. Krebs, C. J. 2001. Ecology. 5th ed. Pearson, Benjamin-Cummings, San Francisco.

40. Kuramae-Izioka, E. 1997. A rapid, easy and high yield protocol for total genomic DNA isolation of Colletotrichum gloeosporioides and Fusarium oxysporum. Revista UNIMAR 19:683-689.

41. Linde, C. C., Liles, J. A., and Thrall, P. H. 2010. Genetic expansion of randomly mating founder populations of Alternaria brassicicola infecting Cakile maritima in Australia. Appl. Environ. Microbiol. 76(6):1946-1954.

42. Linde, C. C., Zhan, J., and McDonald, B. A. 2002. Population structure of Mycosphaerella graminicola: From lesions to continents. Phytopathology 92:946-955.

43. Luikart, G., Allendorf, F. W., Cornuet, J. M., and Sherwin, W. B. 1998. Distortion of allele frequency distributions provides a test for recent population bottlenecks. J. Hered. 89:238-247.

44. Lushai, G., Loxdale, H. D., and Allen, J. A. 2003. The dynamic clonal genome and its adaptive potential. Biol. J. Linn. Soc. 79:193-208.

45. Lynch, M. 1984. Destabilizing hybridization, general-purpose genotypes and geographic parthenogenesis. Qrt. Rev. Biol. 59:257-290.

46. MacKenzie, S. J., Peres, N. A., Barquero, M. P., Arauz, L. F., and Timmer, L. W. 2009. Host range and genetic relatedness of Colletotrichum acutatum isolates from fruit crops and leatherleaf fern in Florida. Phytopathology 99:620-631.

47. Madden, L. V., Yang, X., and Wilson, L. L. 1996. Effects of rain intensity on splash dispersal of Colletotrichum acutatum. Phytopathology 86:864874.

48. Manly, B. F. J. 1991.Randomization and Monte Carlo Methods in Biology. Chapman \& Hall, London.

49. Marcelino, J., Giordano, R., Gouli, S., Gouli, V., Parker, B. L., Skinner, M., TeBeest, D., and Cesnik, R. 2008. Colletotrichum acutatum var. fioriniae (teleomorph: Glomerella acutata var. fioriniae var. nov.) infection of a scale insect. Mycologia 100:353-374.

50. Marques, J. P. R., Amorim, L., Spósito, M. B., Marin, D. R., and Appezzato-da-Glória, B. 2013. Infection of citrus pollen grains by Colletotrichum acutatum. Eur. J. Plant Pathol. 136:35-40.

51. Maynard Smith, J., Smith, N. H., O'Rourke, M., and Spratt, B. G. 1993. How clonal are bacteria? Proc. Natl. Acad. Sci. USA 90:4384.

52. McDonald, B. A., and Linde, C. 2002. The population genetics of plant pathogens and breeding strategies for durable resistance. Euphytica 124:163-180

53. Milgroom, M. G. 1996. Recombination and the multilocus structure of fungal populations. Annu. Rev. Phytopathol. 34:457-477.

54. Nei, M. 1978. Estimation of average heterozygosity and genetic distance from a number of individuals. Genetics 89:538-590.

55. Nguyen, P. T. H., Pettersson, O. V., Olsson, P., and Liljeroth, E. 2010. Identification of Colletotrichum species associated with anthracnose disease of coffee in Vietnam. Eur. J. Plant Pathol. 127:73-87.

56. Parks, J. C., and Werth, C. R. 1993. A study of spatial features of clones in a population of bracken fern, Pteridium aquilinum (Dennstaedtiaceae). Am. J. Bot. 80:537-544.

57. Peres, N. A., MacKenzie, S. J., Peever, T. L., and Timmer, L. W. 2008. Postbloom fruit drop of citrus and key lime anthracnose are caused by distinct phylogenetic lineages of Colletotrichum acutatum. Phytopathology 98:345-352.

58. Peres, N. A., Timmer, L. W., Adaskaveg, J. E., and Correll, J. C. 2005. Lifestyles of Colletotrichum acutatum. Plant Dis. 89:784-796.

59. Porto, O. M., Rossetti, V. V., and Dornelles, C. M. M. 1979. Queda de frutos jovens de citros, causada por Colletotrichum sp. no Rio Grande do
Sul. Pages 681-692 in: Proc. V Soc. Bras. Frutic. Congr. Pelotas, Brazil.

60. Pritchard, J. K., Stephens, M., and Donnelly, P. 2000. Inference of population structure using multilocus genotype data. Genetics 155:945-959.

61. Roe, A. D., Rice, A. V., Coltman, D. W., Cook, J. E. K., and Sperling, F. A. H. 2011. Comparative phylogeography, genetic differentiation and contrasting reproductive modes in three fungal symbionts of a multipartite bark beetle symbiosis. Mol. Ecol. 20:584-600.

62. Screenivasaprasad, S., Sharada, K., Brown, A. E., and Mills, P. R. 1996. PCR-based detection of Colletotrichum acutatum on strawberry. Plant Pathol. 45:650-655.

63. Silva-Junior, G. J., Spósito, M. B., Marin, D. R., Ribeiro-Junior, P. J., and Amorim, L. 2014. Spatiotemporal characterization of citrus postbloom fruit drop in Brazil and its relationship to pathogen dispersal. Plant Pathol. 63:519-529.

64. Slatkin, M. 1995. A measure of population subdivision based on microsatellite allele frequencies. Genetics 139:457-462.

65. Smouse, P. E., and Peakall, R. 1999. Spatial autocorrelation analysis of individual multiallele and multilocus genetic structure. Heredity 82:561573.

66. Spencer, C. C., Neigel, J. E., and Leberg, P. L. 2000. Experimental evaluation of the usefulness of microsatellite DNA for detecting demographic bottlenecks. Mol. Ecol. 9:1517-1528.

67. Stenberg, P., Lundmark, M., and Saura, A. 2003. MLGsim: A program for detecting clones using a simulation approach. Mol. Ecol. Notes 3:329331.

68. Stoddart, J. A., and Taylor, J. F. 1988. Genotype diversity: estimation and prediction in samples. Genetics 118:705-711.

69. Stukenbrock, E. H., Banke, S., and McDonald, B. A. 2006. Global migration patterns in the fungal wheat pathogen Phaeosphaeria nodorum. Mol. Ecol. 14:743-752.

70. Sutton, B. C. 1992. The genus Glomerella and its anamorph Colletotrichum. Pages 1-26 in: Colletotrichum: Biology, Pathology, and Control. J. A. Bailey and M. J. Jeger, eds. CAB International, Wallingford, UK.

71. Talgø, V., Aamot, H. U., Strømeng, G. M., Klemsdal, S. S., and Stensvand, A. 2007 Glomerella acutata on highbush blueberry (Vaccinium corymbosum L.) in Norway. Online. Plant Health Progress.

72. Talhinhas, P., Sreenivasaprasad, S., Neves-Martins, J., and Oliveira, H. 2005. Molecular and phenotypic analyses reveal association of diverse Colletotrichum acutatum groups and a low level of C. gloeosporioides with olive anthracnose. Appl. Environ. Microbiol. 71(6):2987-2998.

73. Taylor, J. W., Jacobson, D. J., and Fisher, M. C. 1999. The evolution of asexual fungi: Reproduction, speciation and classification. Annu. Rev. Phytopathol. 37:197-246.

74. Timmer, L. W., Agostini, J. P., Zitko, S. E., and Zulfiqar, M. 1994. Postbloom fruit drop, an increasingly prevalent disease of citrus in the Americas. Plant Dis. 78:329-334.

75. Turgeon, B. G. 1998. Application of mating type gene technology to problems in fungal biology. Annu. Rev. Phytopathol. 36:115-137.

76. Ureña-Padilla, A. R., MacKenzie, S. J., Bowen, B. W., and Legard, D. E. 2002. Etiology and population genetics of Colletotrichum spp. causing crown and fruit rot of strawberry. Phytopathology 92:1245-1252.

77. Weir, B. S. 1996. Genetic Data Analysis. 2nd ed. Sinauer, Sunderland, MA.

78. White, T. J., Bruns, T., Lee, S., and Taylor, J. W. 1990. Amplification and direct sequencing of fungal ribosomal RNA genes for phylogenetics. Pages 315-322 in: PCR Protocols: A Guide to Methods and Applications. M. A. Innis, ed. Academic Press, Inc., New York.

79. Zulfiqar, M., Brlansky, R. H., and Timmer, L. W. 1996. Infection of flower and vegetative tissues of citrus by Colletotrichum acutatum and $C$. gloeosporioides. Mycologia 88:121-128. 